\title{
Lexical language-related episodes in pair and small group work
}

\author{
María del Pilar García MAYo \& Nora ZEITLER* \\ Universidad del País Vasco (UPV/EHU)
}

Received: 28/03/2016. Accepted: 24/08/2016.

\begin{abstract}
The present study investigates whether learner set up in interaction, namely in pairs or small groups, influences the frequency and outcome of lexical language-related episodes (LREs) and L2 vocabulary learning. Thirty Spanish English as a foreign language (EFL) university learners took part in the study. They worked in four groups and seven pairs on the same collaborative writing task. Research was carried out on the course of five weeks as a pre- and post- vocabulary task and an individual writing task were administered to assess vocabulary learning and retention. The quantitative analysis of the data showed that there was no significant difference between the performance of pairs and groups, although the latter produced slightly more lexical LREs than pairs and were able to solve most of them correctly. However, from a qualitative point of view, the findings suggest that small group work leads to slightly better results than pair work as the different members obtain benefits from their peers' linguistic knowledge.
\end{abstract}

KEYWORDS: pair, small group, language-related episodes, collaborative work, EFL.

\section{INTRODUCTION}

Group and pair activities involving interactions and discussions are a common practice in foreign language classrooms. There are a number of pedagogical reasons which support the use of these activities, such as increased opportunities to use the target language, the promotion of learner-autonomy and self-directed learning (Crookes \& Chaudron, 2001). Learner-learner interactions hold a number of benefits for students which have been widely investigated throughout the past decades. The Interaction Hypothesis (Long, 1996; Pica, 1994) claims that during interaction the learner receives feedback, notices differences

*Address for correspondence: María del Pilar García Mayo. Departamento de Filología Inglesa y Alemana, Traducción e Interpretación, Universidad del País Vasco / Euskal Herriko Unibertsitatea (UPV/EHU), Facultad de Letras, Vitoria-Gasteiz, Spain; e-mail: mariapilar.garciamayo@ehu.eus. 
between his production and the target language and is therefore pushed to modify his own output (Swain, 1985). The learner acquires new linguistic forms as a result of negotiating for meaning in order to address a communication problem. Other benefits of interaction include the fact that group and pair activities offer more opportunities for students to use the second language (L2) than in a teacher-led classroom (Long \& Porter, 1985; Storch \& Aldosari, 2013) and a lower anxiety context for students to practice the target language (Richard, 2006).

Over the past three decades most research on learner-learner or learner-native speaker interaction has been carried out within the interactionist framework (see García Mayo \& Alcón Soler, 2013; Keck, Iberri-Shea, Tracy-Ventura \& Wa-Mbaleka, 2006; and Mackey \& Goo, 2007 for reviews). However, some more recent studies have been conducted within the framework of Sociocultural Theory (SCT), inspired by the ideas of the Soviet psychologist Lev Vygotsky (1978). According to him, human cognitive development is a socially situated activity mediated by language. Knowledge is socially constructed by interaction and is then internalized: individuals learn how to carry out a new function with the help of an expert (a more capable member of the community) and then they can perform it individually. The expert's help can make the novice perform beyond his actual level, a process referred to in the literature as scaffolding (Wood, Bruner \& Ross, 1976). L2 researchers have adapted Vygotsky's theory and have focused on learners' collaboration when solving languagerelated problems, leading to the co-construction of new language knowledge (GánemGutiérrez, 2013; Swain, 2000; Swain \& Lapkin, 2013). Studies conducted from a SCT perspective encourage the use of collaborative tasks because it is by completing them that learners solve language-related problems together.

The present study follows this recent line of investigation in order to examine and compare the production of lexical language-related episodes (LREs) (Swain \& Lapkin, 1998) in pair and small group work in a collaborative writing task. As Fernández Dobao mentions, from a SCT perspective "[...] a large number of participants represents more knowledge and linguistic resources to share. This means a higher probability to find a correct solution to the language-related problems encountered" (2014: 501). Although there is some empirical research on comparisons between individual and pair work, studies comparing pair work to small group work in an English as a foreign language (EFL) setting are scarce. Second language and foreign language contexts differ considerably with respect to quality and quantity of exposure to the target language. In foreign language settings, teachers have less class time contact with their students and L2 input opportunities are limited, both inside and outside the classroom (Philp \& Tognini, 2009). Inspired by Fernández Dobao's (2014) original study on the opportunities that pair and small group interaction offer for collaborative dialogue and L2 vocabulary learning with English learners of Spanish in the USA, the present study aims to fill this research gap by studying pair and group work in an EFL setting. 


\section{COLLABORATIVE WRITING TASKS AND THE IMPACT OF LEARNER SETUP}

Swain (2006) claims that collaborative dialogue is a crucial source of learning because it is by means of a process she refers to as languaging that learners make meaning of their interaction and also shape their knowledge and experience. Collaborative dialogue has been operationalized through LREs, defined by Swain and Lapkin as "any part of dialogue where the students talk about the language they are producing, question their language use, or correct themselves or others" (1998: 326). LREs are triggered when learners discuss the language they are using in order to solve their language-related problems and have been claimed to represent learning in progress (Gass \& Mackey, 2007).

LREs are analyzed on the basis of their nature (form-based or lexical-based) and on their outcome (correctly resolved, incorrectly resolved or unresolved). In form-based LREs attention is focused on issues such as phonology and morphosyntax, while in lexical-based LREs attention is focused on word-related searches. Recent research on the effect of task modality on the nature of LRE (Adams \& Ross-Feldman, 2008; García Mayo \& Azkarai, 2016) has shown that speaking tasks lead to more meaning-focused LREs, whereas those that also include a writing component trigger more form-focused LREs.

The focus of the present study is on lexical LREs. Following Swain and Lapkin (1998), lexical LREs are defined as parts of an interaction where learners talk about or discuss their vocabulary use. This includes segments where learners clarify the meaning of a word, search for new vocabulary, choose between alternative lexical items or determine the correct spelling and pronunciation of a word (Fernández Dobao, 2014). Example 1 shows a correctly resolved lexical LRE. Two students discuss the meaning of 'to be in touch', which is correctly provided by learner 1 in turn 3 by expressing it in Spanish (mantener contacto o conectar):

\section{Example 1}

1Learner 1: $\quad$ to be in touch eh to be in touch

2Learner 2: what is the meaning of it?

3 Learner 1: $\quad$ para mantener contacto o (to be in contact or)

4Learner 2: $\quad$ conectar (to connect)

5Learner 1: si para (yes to) meet people to be in touch with

6Learner 2: with other people

7Learner 1: vale (alright)

(Basterrechea \& García Mayo, 2013: 32)

Example 2 represents an incorrectly resolved lexical LRE. The two students are carrying out a picture placement task, and Susana is looking for the word 'dustpan' in 
English. In turn 2, Miguel provides the word 'taker', which Susana accepts, but which is incorrect:

Example 2

1 Susana: I don't know how to say in English this word. The rubbish, uff...

2 Miguel: $\quad$ Take, taker!

3 Susana: Taker!

(Azkarai, 2013: 88)

Finally, example 3 illustrates a lexical LRE that is left unresolved. A male and a female learner discuss the word 'wheel' while completing a picture placement task. The female learner does not know the correct English word for it and asks her partner. However, he does not solve her doubt and the LRE remains unresolved:

Example 3

1 Female learner: $\quad$ Oh! Ah, no? Mine's .. I don't know if it's a ball or a racquet ..

2 Male learner: No

3 Female learner: $\quad$ Eh .. like to round and round and round all the time.

4Male learner: $\quad$ Yeah, no.

5 Female learner: $\quad$ No? So, I've one machine of that here in the park.

6 Male learner: $\quad$ Ok.

7Female learner: $\quad$ I don't know the name.

(Azkarai \& García Mayo, 2012: 263)

A variety of research specifically focuses on and supports the use of collaborative writing tasks, where two or more learners write a single text together (García Mayo \& Azkarai, 2016; Swain, 2000, 2001; Swain \& Lapkin, 2001). Having two or more learners working on one jointly written text makes them talk and discuss the language they use as they try to solve possible linguistic problems together, resulting in LREs. As Fernández Dobao states, learners "engage in language-mediated cognitive activities like formulating and testing hypotheses, offering and testing new input and correcting themselves or others" (2014: 498).

Recent research has compared the written output of learners working individually, in pairs or in groups. What these studies address is whether or not the number of participants influences the outcome of the written output. A first group of studies considered whether there were differences between writing in pairs or writing individually. Thus, Storch (1999) carried out a study in an English as a second language (ESL) course at an Australian university. Eight students with seven different L1 backgrounds completed three tasks, a cloze exercise, a text reconstruction task and a composition task. The researcher was interested in 
whether collaboration would have an impact on accuracy and reported that the texts produced by the pairs were grammatically more accurate than those produced individually.

In a subsequent study, Storch (2005) compared pair and individual work on a short composition task based on a visual prompt. The study was also conducted in an ESL writing class. Again, the L1 background of the students was mixed, but most of them were Asian. Five learners completed the task individually and 14 in pairs. Her findings showed that pairs needed more time for the task and produced shorter texts, which were however more accurate and complex than those written by individuals on their own. Examining the oral interactions of pairs, Storch found that, unlike individual learners, they had opportunities to pool their knowledge and provide feedback to one another.

Storch and Wigglesworth (2007) carried out a study which tried to make up for the small database in Storch (2005). This time they considered the performance of 24 pairs and 24 individual learners in two writing tasks, a report and an argumentative essay. The study was set in an ESL context and most participants were Asian. Pairs had more time to complete the task than individuals. Their results showed that there were no differences regarding complexity and fluency, but texts written by pairs were significantly more accurate than those written by only one person. The analysis of the interaction between pairs showed that they discussed the language they used in numerous LREs, both lexical and grammatical, which, according to Storch and Wigglesworth, led to more accurate texts. Similar results were reported by Wigglesworth and Storch (2009).

Although the studies briefly summarized above were not specifically designed to address whether collaborative tasks led to L2 learning, others were. Thus, Kim (2008) compared the pair and individual performance of 32 Korean L2 learners. They were asked to complete a dictogloss while thinking aloud. The number of LREs generated was equal for both individuals and pairs; however, pairs performed better in posttests. Nassaji and Tian (2010) used two different tasks (a cloze task and an editing task) on English phrasal verbs to compare pair and individual work. The study was conducted in two low-intermediate ESL classrooms in a Canadian university. There were a total of 26 participants with six different language backgrounds. Findings showed that pair results were more accurate than those for individuals, although statistically significant differences could not be reported. In sum, learners working in pairs seem to generally obtain more accurate results than learners working individually, suggesting that pair work holds benefits for L2 learning.

McDonough (2004) was an early study that considered instructors' and learners' perceptions about the use of pair and small group activities and whether the learning opportunities attributed to those activities occurred in an intact classroom. Her aim was also to investigate whether learners who actively participated during the pair and small group activities showed improved production of the target form chosen, conditional clauses. A total of 16 Thai university level learners completed different tasks over an eight-week period. The findings of the study indicated that participation in the activities led to more accurate and 
improved production, even if learners did not find them very useful (unlike the Spanish as a foreign language [SFL] learners in Fernández Dobao and Blum [2013]).

Fernández Dobao (2012) was the first study to compare group, pair and individual work in collaborative writing tasks in the L2 classroom. The study was conducted with six intermediate classes of SFL in the USA. 21 learners worked individually, 30 in pairs and 60 in groups of four on a jigsaw task. They had to rearrange the pictures provided and produce a written text. Fernández Dobao examined whether the number of participants had an effect on the fluency, complexity and accuracy of the written products and on the frequency and nature of the oral interaction produced in pairs and groups. Her findings showed that groups produced more LREs than pairs and also a higher number of correctly resolved LREs. Consequently, texts written by groups were not only more accurate than those written individually, but they were also more accurate than those written by pairs. Although group work offered learners fewer opportunities to actively participate in the conversation, it led to better and more accurate results.

More recently, Fernández Dobao (2014) focused on vocabulary learning in collaborative writing tasks and compared pair and small group work. The participants were those in the 2012 study. There were 15 groups of four learners and 25 pairs of intermediate SFL learners. Results showed that small groups produced more lexical LREs than pairs and that more LREs were correctly resolved. It was also found that although learners had fewer opportunities to contribute to the conversation when working in small groups, there did not seem to be a negative effect on the learners' rate of retention of the lexical knowledge which was co-constructed in conversation. Learners seemed to benefit from the LREs when they were actively involved in the conversation, as well as when they were acting as observers. Therefore, Fernández Dobao concluded that small group interaction led to significantly more opportunities for L2 vocabulary learning than pair interaction.

From the studies that have been conducted so far, it seems clear that collaboration has a positive effect on task performance, supporting the role of collaborative activities in the second and foreign language classroom. Moreover, it seems to be the case that small group work generally leads to better and more accurate results than pair work. However, as mentioned above, little research has been conducted in foreign language settings and, with the exception of Fernández Dobao (2014), even less on particular aspects of language learning such as vocabulary. The present study aims to fill in this gap by extending the database in foreign language settings where access to input is normally limited to the classroom. 


\section{THE PRESENT STUDY}

This study examines lexical LREs in pair and small group task-based interaction in an EFL context with Spanish participants. It is a partial replication of Fernández Dobao (2014) and, therefore, the same two research questions guide this investigation:

1. Does learner setup, pair vs. small group, influence the frequency and outcome of lexical LREs?

2. Does learner setup, pair vs. small group, influence the opportunities that lexical LREs offer for L2 vocabulary learning?

\subsection{Participants}

Thirty first year undergraduate English Studies students (20 female, 10 male) at a major Spanish university participated in the study. Their average age was 19 (range 17-26) and their proficiency level intermediate (Oxford placement test, Syndicate, U.C.L.E., 2001). A total of 16 students worked in groups of four members and 14 in pairs, so there were 4 groups and 7 pairs. All were enrolled in a course entitled 'Oral English', which they attended twice per week during the first semester of studies. The course was divided into two classes with different time schedules on the same weekdays. The teacher allowed research to take place on three days for each class over a course of five weeks. Participants from one class worked in groups, participants from the other class worked in pairs.

\subsection{Collaborative task}

As this study is a partial replication of Fernández Dobao (2014), the same material was used for the experiment. The collaborative writing task was based on a visual prompt, consisting of a set of 15 pictures (González Sáinz, 1999). The task for the students was to put the pictures in order, create a story together and then write it down. There was no pre-established order for the pictures and the students had to decide how to sequence them. Each pair and group was asked to produce one single text. Before the task the participants were not provided with any vocabulary instruction.

\subsection{Pretest and posttest}

The same type of pre- and posttests employed by Fernández Dobao (2014) were used in this study, but adapted to the EFL context. In order to assess learning and retention, two different instruments were used, a vocabulary task and an individual writing task. These instruments were used because they helped to assess the learners' productive knowledge of the 
vocabulary that they had discussed in their LREs and whether they were able to individually use the items that they had first used in collaboration with their group or pair.

A vocabulary task functioned as a pretest in order to assess which words the participants were already familiar with before the collaborative task. Similarly, the same vocabulary task was administered as a posttest in order to observe learners' development and whether they were able to move from an incorrect to a correct response on the basis of the oral interaction they had had. A total of 20 lexical items was included in the task, the same for the pre- and posttest, only the order was changed (see Appendix for vocabulary pretest). As a second posttest, participants were asked to perform an individual writing task. Handing out the same picture prompt to each participant again, they were asked to write down the same story they came up with collaboratively during the experiment. The individually written texts contained evidence as to whether students were able to use the lexical knowledge they co-constructed with their pair or group working on their own.

\subsection{Procedure}

As mentioned above, research was carried out over a course of five weeks, spending three days in each of the two classes, respectively. Data collection started in week seven of the first semester so students were already familiar with each other. Table 1 illustrates how the data collection was carried out. It shows which tests were conducted on which days, with which participants and how much time it took them to complete the task:

\begin{tabular}{|c|l|l|c|}
\hline WEEK & \multicolumn{1}{|c|}{ TYPE OF TEST } & TIME & PARTICIPANTS \\
\hline 1 & $\begin{array}{l}\text { Oxford Placement Test } \\
\text { Background questionnaire } \\
\text { Vocabulary task }\end{array}$ & approx. 45 minutes & Groups \\
\hline 2 & Collaborative writing task & 30 minutes per group & Groups \\
\hline 3 & $\begin{array}{l}\text { Vocabulary task } \\
\text { Individually written text }\end{array}$ & approx. 40 minutes & Groups \\
\hline 3 & $\begin{array}{l}\text { Oxford Placement Test } \\
\text { Background questionnaire } \\
\text { Vocabulary task }\end{array}$ & approx. 45 minutes & Pairs \\
\hline 4 & Collaborative writing task & 30 minutes per pair & Pairs \\
\hline 5 & $\begin{array}{l}\text { Vocabulary task } \\
\text { Individually written text }\end{array}$ & approx. 40 minutes & Pairs \\
\hline
\end{tabular}

Table 1. Data collection planning.

On the first day the participants were asked to fill in the pretests, consisting of the Oxford Placement Test, a background questionnaire and the vocabulary task. One week later, students were organized into groups or pairs. The participants were not allowed to use any kind of dictionary or other material during the experiment and their oral interactions during the experiment between all groups and pairs were audio-recorded. On the third day, one week 
after the collaborative tasks, posttests were carried out. The participants were given as much time as they needed in order to complete them. They were asked to complete the vocabulary task, with an altered order for the items, and the individual writing task.

\subsection{Data coding and analysis}

\subsubsection{Language-related episodes}

All recorded oral interactions of the groups and pairs were transcribed (4 hours and 10 minutes) and coded for lexical LREs. As mentioned above, in these episodes participants may discuss the meaning of a word, search for a new word, choose between different words or try to figure out the correct spelling or pronunciation of a word.

As a next step, the lexical LREs were classified as correctly resolved, unresolved or incorrectly resolved. Following Fernández Dobao (2014: 504), the length of the LREs was also taken into account and was operationalized as the number of turns. An episode started when a lexical problem was raised and it ended when it was either solved or the participants changed to another topic; therefore, each LRE deals with one lexical problem. If participants discussed the same problem several times throughout the interaction, this was tallied as one LRE. The two researchers coded the database independently and reached a $97 \%$ agreement. After a second round of coding, 100\% agreement was obtained.

Example 4, taken from the group data, presents a correctly resolved lexical LRE. In the first turn, student G1S1 (= group 1, student 1) looks for the word 'immediately' or 'instantly', which student G1S2 provides in the second turn. Both of them repeat the word, and in the sixth turn G1S3 provides the correct spelling of the word. In the last turn, G1S1 accepts the word and its spelling and repeats it one more time:

\section{Example 4}

1 G1S1: Asleep. Without... they felt asleep instant, instant

2G1S2: Immediately

3 G1S1: Immediately

4G1S2: Immediately

5 G1S1: Immediately

6G1S3: Double m.

7 G1S1: I know. Imme- dia- tely.

In example 5, P3S1 (= pair 3, student 1) suggests using 'gardening shop' but none of the members of the pair is able to recall it. As they do not manage to find a solution to the lexical problem in this case, the LRE is left unresolved: 


\section{Example 5}

1 P3S1: Yeah, they met near the ferretería y jardinería Gomez.

2P3S2: Wait wait wait wait wait what?

3 P3S1: Favorite pub and to the shop where they met for the first time. That was you know for the .....

4P3S2: How do you call this?

5 P3S1: I don't know.

Example 6 features an incorrectly resolved LRE. The group looks for the word 'fortune teller', but G4S2 is not able to express the term 'psychic' correctly, which is an acceptable alternative for the word they want to use. In turn 4, G4S1 suggests the word 'wizard', which is not a correct solution to the lexical problem. Ultimately, G4S3 provides the term 'futurologist', another incorrect choice in this case:

\section{Example 6}

1 G4S2: And then she go to a physic or

2G4S3: How do you call this?

3 G4S2: Physic (Spanish) creo.

4 G4S1: Wizard.

5 G4S4: She decided to visit a

6 G4S3: No, futurologist, futurologist or [...] Futurologist. Like it sounds.

\subsubsection{Vocabulary learning and retention}

The pre- and posttest vocabulary tasks were examined for vocabulary learning and retention. The responses provided by participants were compared for the two tests, but only those lexical items that learners had previously talked about while engaged in their LREs were considered. Following Fernández Dobao's methodology, while both correctly and incorrectly resolved LREs were taken into account for analysis, unresolved LREs had to be left out as whatever changes that one could find between the pre- and post- vocabulary task could not be related to an unresolved LRE.

Following Fernández Dobao (2014), three categories were created in order to sort participants' responses from the vocabulary task. These three categories were learning new knowledge, consolidation of existing knowledge and missed opportunity for learning. An instance of learning was identified when a learner used a different word in the posttest compared to the pretest after having discussed it with his peers in an LRE. When a participant used a word that had been co-constructed in an LRE but he had also used it in the pretest, this was coded as consolidation of existing knowledge. A missed opportunity for learning was noted when a learner made use of a word that did not come up in an LRE or when the response was incorrect, e.g. misspelled. 
The following example illustrates a correctly resolved LRE for the word 'psychic'. The two learners agree on the correct spelling, provided by P6S2. The fact that student P6S1 does not change his response from the pre- to the posttest demonstrates that he did not gain new knowledge of the word co-constructed in the LRE. This is an instance of missed opportunity for learning. P6S2 uses the same word in both versions of the test, which is an instance of consolidation of existing knowledge:

Example 7

1 P6S1: To see a psychic?

2P6S2: Yes to see a psychic.

3 P6S1: How how do you write psychic? I put it wrong in the exam.

4P6S2: P-S

5 P6S1: P

6P6S2: Y-C-H

7P6S1: Psychic.

8P6S2: Yes.

9P6S1: To see a psychic.

\begin{tabular}{|c|c|c|c|}
\hline LEARNER & PRETEST & POSTTEST & ANALYSIS \\
\hline P6S1 & predicter & predicter & Missed opportunity for learning. \\
\hline P6S2 & psychic & psychic & Consolidation of existing knowledge. \\
\hline
\end{tabular}

Example 8 shows another correctly resolved lexical LRE where two learners discuss the item 'travel agency'. P3S2 reflects on the use of the word and concludes that 'travel agency' is the correct choice instead of 'trip agency', which is indeed incorrect. Both of them agree to use 'travel agency'. From the comparison of the pre- and posttest it is obvious that P3S1 consolidates existing knowledge, while P3S2 changes her response in the posttest to the correct solution previously established in the LRE. Therefore, in P3S2's case, this is an instance of learning new knowledge:

\section{Example 8}

1 P3S2: Eh she was going to a

2P3S1: She went to a travel agency

3P3S2: To eh this one, travel agency. Not trip agency but travel agency. Okay.

4P3S1: And why the remark?

5 P3S2: Because I thought you wrote down trip agency, whatever. Okay, so she went to New York.

6P3S1: Travel agency and .... 


\begin{tabular}{|c|c|c|c|}
\hline LEARNER & PRETEST & POSTTEST & ANALYSIS \\
\hline P3S1 & travel agency & travel agency & Consolidation of existing knowledge. \\
\hline P3S2 & trip's agency & travel agency & Learning new knowledge. \\
\hline
\end{tabular}

The second posttests, the individually written tests, were also examined for retention. Retention was noted when a participant independently used a word in his text previously discussed with his peers in an episode. Lack of retention was coded for when the learner failed to come up with the same lexical item discussed in an LRE while referring to the same concept.

The following example is taken from the group data. It shows a short LRE of 5 turns where the group discusses the spelling of 'cycling'. From the collaboratively written text it was clear that they had chosen the correct spelling:

\section{Example 9 \\ 1 G1S3: Cycling isn't with one i? \\ 2G1S1: I think that it's \\ 3 G1S3: Whereas of two? \\ 4G1S1: Skiing with two i \\ 5G1S2: Yeah.}

The examination of the individually written texts from this group shows that G1S1 and G1S2 remember the correct spelling of the word and use it correctly in their texts. As the item 'cycling' also appeared in the vocabulary pretest, it is obvious that both G1S1 and G1S2 consolidate existing knowledge. G1S3 did not mention the idea of cycling in her individually written story, so no conclusion can be drawn as to whether she retained the knowledge built in the LRE or not. Student G1S4 does not remember the correct spelling of the word and misspells it in her story; therefore, an instance of lack of retention was noted:

\begin{tabular}{|c|c|c|}
\hline LEARNER & INDIVIDUALLY WRITTEN TEXT & ANALYSIS \\
\hline G1S1 & when they were cycling & Retention. \\
\hline G1S2 & his wife cycling & Retention. \\
\hline G1S3 & ---- & No mention. \\
\hline G1S4 & next activity was cicling (misspelled) & Lack of retention. \\
\hline
\end{tabular}

Example 10 shows P1S1 and P1S2 discussing the spelling of the word 'psychic', which is correctly resolved and accepted by P1S1 in turn 7. However, the analysis of their individually written stories shows that only P1S2 used the item in her text while P1S1 chose the word 'futurologist', an incorrect choice in this case. As this item also occurs in the vocabulary pretest we can conclude that P1S2 consolidated existing knowledge while P1S1 had a missed opportunity for learning in this case, and he did not remember the word 'psychic' from the LRE, which also resulted in a lack of retention: 
Example 10

1 P1S1: One day ehm she decided on going to psychic

2P1S2: Psychic

3 P1S1: How is it spelled?

4P1S2: C-H-I

5P1S1: C-H

6P1S2: I-C

7P1S1: Psychic yeah

8P1S2: I think it's with Y there, I don't know.

\begin{tabular}{|c|c|c|}
\hline LEARNER & INDIVIDUALLY WRITTEN TEXT & ANALYSIS \\
\hline P1S1 & Futurologist & Lack of retention. \\
\hline P1S2 & Psychic & Retention. \\
\hline
\end{tabular}

\section{RESULTS}

Our first research question considered whether learner setup, pair vs. small group, could influence the frequency and outcome of lexical LREs. In order to answer this question, the oral interactions between groups and pairs during the collaborative writing task were analyzed. The lexical LREs were compared by taking frequency, length and resolution into account. Table 2 features the results regarding frequency of LREs. It shows that groups and pairs focused their attention almost equally often on lexis: a total of 45 lexical LREs was generated by the four groups, with an average of 11.25 LRE per group, while a total of 70 lexical LREs was produced by the seven pairs, which comes down to an average of 10 LREs per pair. In order to test for statistical significance, the Independent samples Mann-Whitney $\mathrm{U}$ Test was carried out. There was no statistically significant difference in frequency between groups and pairs $(\mathrm{U}=11,5, p=0.63)$ :

\begin{tabular}{|l|c|r|r|r|r|c|}
\cline { 2 - 7 } \multicolumn{1}{c|}{} & \multicolumn{3}{c|}{ GROUPS (4) } & \multicolumn{3}{c|}{ PAIRS (7) } \\
\cline { 2 - 7 } \multicolumn{1}{c|}{} & $\mathbf{N}$ & \multicolumn{1}{c|}{ M } & \multicolumn{1}{c|}{ SD } & N & M & SD \\
\hline Lexical LREs & 45 & 11.25 & 6.39 & 70 & 10 & 4.32 \\
\hline Turns & & 7.6 & 5.6 & & 6.04 & 3.14 \\
\hline
\end{tabular}

Table 2. Frequency and length of lexical LREs in groups and pairs.

Regarding length of the lexical LREs, Table 2 also shows that results for groups and pairs are very similar. Lexical LREs produced by groups are slightly longer than those produced by pairs: LREs generated by groups had an average of 7.6 turns while LREs produced by pairs had an average of 6.04 turns. There was no statistically significant difference in the length of LREs produced by groups and pairs $(\mathrm{U}=10,0, p=0,45)$. 
As for the outcome of the LREs, Table 3 shows that groups were more successful at solving lexical LREs than pairs. On average, each group solved 9 lexical LREs correctly while each pair solved 6.71. The findings have to be interpreted with caution, though, as the difference between groups and pairs is not statistically significant $(\mathrm{U}=11,0, p=0.56$ ). However, percentages give a clear indication that groups had indeed more correctly resolved LREs than pairs: $80 \%$ of all lexical LREs generated by groups were solved correctly, while pairs only solved $67 \%$ of their LREs:

\begin{tabular}{|l|r|r|r|r|r|c|c|c|}
\cline { 2 - 9 } \multicolumn{1}{c|}{} & \multicolumn{4}{c|}{ GROUPS (4) } & \multicolumn{4}{c|}{ PAIRS (7) } \\
\hline LREs & N & \multicolumn{1}{c|}{ M } & \multicolumn{1}{c|}{ SD } & \multicolumn{1}{c|}{$\%$} & N & M & SD & \% \\
\hline Incorrect & 36 & 9 & 5.72 & $80 \%$ & 47 & 6.71 & 3.77 & $67 \%$ \\
\hline Unresolved & 5 & 1.25 & 0.5 & $11 \%$ & 17 & 2.43 & 0.98 & $24 \%$ \\
\hline
\end{tabular}

Table 3. Outcome of lexical LREs for groups and pairs.

As can be seen in Table 3, the percentage for unresolved LREs was exactly the same for both groups and pairs: 9\% of all LREs produced by pairs and by groups were left unresolved. However, the picture is different for incorrectly resolved LREs. While groups solved $11 \%$ of their episodes incorrectly, pairs had more incorrect episodes $(24 \%)$. This comes to an average of 1.25 incorrect episodes per group and 2.43 incorrect episodes per pair, although statistically significant differences cannot be reported $(\mathrm{U}=13,0, p=0,84)$.

The second research question considered whether learner setup, pair vs. small group, could influence the opportunities that lexical LREs offer for L2 vocabulary learning. In order to examine these issues, the data from the pre- and posttests, the vocabulary task and the individually written text were analyzed. Table 4 illustrates results from the vocabulary task. As mentioned above, the vocabulary task did not include all items that participants discussed in their LREs, as it was impossible to know what they would talk about. Only those items included in the vocabulary task and discussed by the learners were part of this analysis. Table 4 displays correctly and incorrectly resolved LREs: 


\begin{tabular}{|c|c|c|c|c|c|c|c|c|c|}
\hline & \multicolumn{4}{|c|}{$\begin{array}{l}\text { LEARNERS IN GROUPS } \\
(\mathbf{N}=16)\end{array}$} & \multicolumn{4}{|c|}{$\begin{array}{c}\text { LEARNERS IN PAIRS } \\
(\mathrm{N}=14)\end{array}$} \\
\hline & & $\mathbf{N}$ & $\mathbf{M}$ & SD & $\%$ & $\mathbf{N}$ & M & SD & $\%$ \\
\hline \multirow[t]{3}{*}{$\begin{array}{l}\text { Correct } \\
\text { LREs }\end{array}$} & $\begin{array}{l}\text { Learning new } \\
\text { knowledge }\end{array}$ & 7 & 0.47 & 0.52 & $19 \%$ & 4 & 0.29 & 0.47 & $22 \%$ \\
\hline & $\begin{array}{l}\text { Consolidation of } \\
\text { existing knowledge }\end{array}$ & 22 & 1.47 & 0.92 & $59 \%$ & 10 & 0.71 & 0.73 & $56 \%$ \\
\hline & $\begin{array}{l}\text { Missed opportunity for } \\
\text { learning }\end{array}$ & 8 & 0.53 & 0.64 & $22 \%$ & 4 & 0.29 & 0.47 & $22 \%$ \\
\hline \multirow[t]{3}{*}{$\begin{array}{l}\text { Incorrect } \\
\text { LREs }\end{array}$} & $\begin{array}{l}\text { Learning new } \\
\text { knowledge }\end{array}$ & 0 & 0 & 0 & $0 \%$ & 1 & 0.07 & 0.27 & $10 \%$ \\
\hline & $\begin{array}{l}\text { Consolidation of } \\
\text { existing knowledge }\end{array}$ & 0 & 0 & 0 & $0 \%$ & 2 & 0.14 & 0.36 & $20 \%$ \\
\hline & $\begin{array}{l}\text { Missed opportunity for } \\
\text { learning }\end{array}$ & 7 & 0.47 & 0.52 & $100 \%$ & 7 & 0.5 & 0.65 & $70 \%$ \\
\hline
\end{tabular}

Table 4. Vocabulary task: evidence of learning.

The analysis revealed that results for groups and pairs were very similar. In groups, new knowledge was learned in 19\% of the correctly resolved LREs, in 59\% of the times the learners consolidated existing knowledge and they missed opportunities for learning in $22 \%$. Findings of the LREs for pairs show that they learned new knowledge from correctly resolved episodes in 22\%, consolidated existing knowledge in $56 \%$ and missed opportunities for learning in $22 \%$. No statistically significant differences were found between groups and pairs regarding learning new knowledge, consolidating existing knowledge or missing opportunities for learning on the basis of the correctly resolved lexical LREs. It should also be noted that incorrectly resolved LREs held opportunities for learners to learn new knowledge, consolidate existing knowledge, miss opportunities for learning and retain knowledge. As seen in Table 4, for groups $100 \%$ of the items resulted in missed opportunities, while only $22 \%$ of the correctly resolved LREs were missed opportunities. For pairs, $70 \%$ of the items were missed opportunities when incorrectly resolved, compared to only $22 \%$ in correctly resolved episodes. These findings show that learners are less likely to retain knowledge from incorrectly resolved LREs, both in pair and group work.

The total number of words learnt by students in groups and pairs was not statistically significant either. Results show that a total of 7 new words was learnt during correctly resolved LREs in groups, an average of 0.47 words per learner. Pairs learnt a total of 4 new words with an average of 0.29 words per learner. Groups consolidated more existing knowledge than pairs, with a total of 22 consolidated words, an average of 1.47 words per student. Pairs consolidated a total of 10 words at an average of 0.71 words per student.

The analysis of the individually written texts provided the possibility to take more items into account but only when the learners chose to use those items in their texts. Table 5 shows the results of the analysis of the individually written texts: 


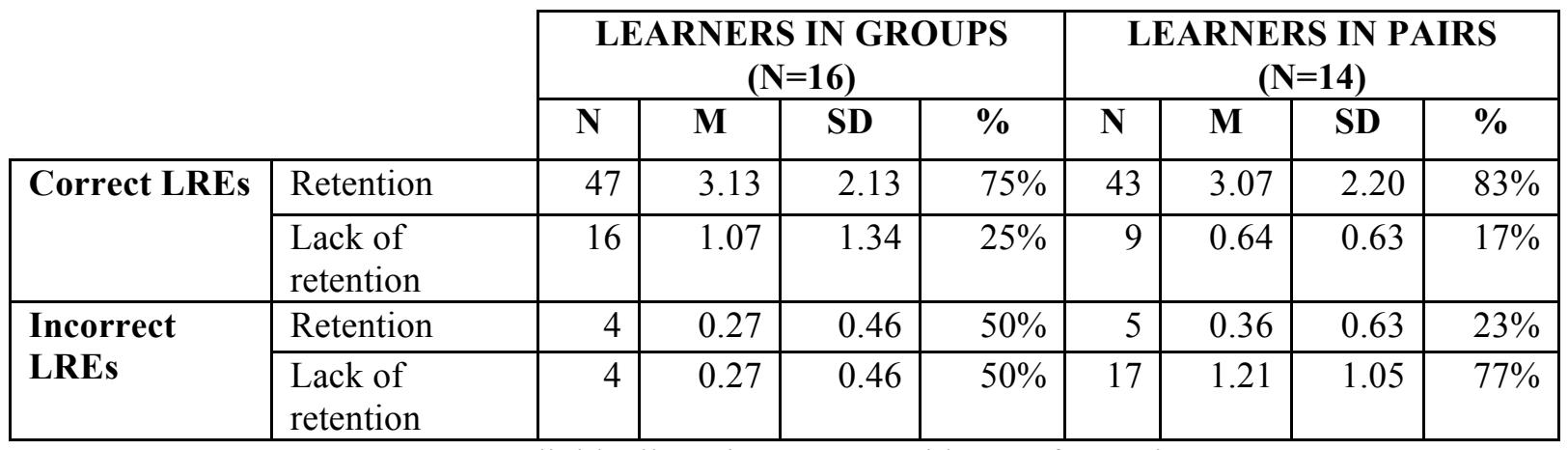

Table 5. Individually written texts: evidence of retention.

Results for groups and pairs are very similar regarding correctly resolved LREs. Participants in groups retained the solutions reached in $75 \%$ of the correctly resolved LREs analyzed, while participants from pairs retained items in $83 \%$ of the cases. A total of 47 words was retained by groups at an average of 3.13 words per learner, while pairs retained a total of 43 words at an average of 3.07 words per learner. The Mann-Whitney U Test confirmed that the difference between pairs and groups was not statistically significant.

\section{DISCUSSION}

In this study we compared the extent to which learner setup, pairs vs. groups, influenced the frequency and outcome of lexical LREs and the opportunities that they offered for L2 vocabulary learning. Watanabe and Swain (2007), when analyzing LREs produced by a small sample size $(n=12)$, considered that any difference under $5 \%$ was probably due to possible error in coding. A difference of 5\% to $10 \%$ was considered as a trend and a difference greater than 10\% was regarded as a difference (Watanabe \& Swain, 2007: 127-128). Fernández Dobao (2014) showed that lexical LREs in groups were significantly more frequent and longer than in pairs. Groups were also more successful at solving them correctly. Findings from the present study could not show statistically significant differences between groups and pairs. However, by taking a closer look at percentages, there is a slight advantage of groups over pairs when it comes to the correct resolution of lexical LREs. In Watanabe and Swain's terminology, a clear difference exists between groups and pairs regarding the correct resolution of lexical LREs ( $80 \%$ vs. 67\%) and their incorrect resolution (11\% vs. 24\%).

It should also be noted that variation occurred not only between groups and pairs, but also among each composition. For instance, one group produced only 3 lexical LREs while another produced a total of 18 . The same goes for pairs: in two instances, pairs only produced a total of 5 lexical LREs, while another pair generated a maximum of 15 . This is an interesting variation which also occurred in Fernández Dobao's (2014) study and which has been noted by Storch (2001) and Watanabe and Swain (2007). These researchers state that 
although participants may be familiar with each other, not all of them can be expected to collaborate with each other in the same way. Some pairs and groups, also in the present study, are found to be more collaborative, and therefore produce more LREs than others. In many cases groups were able to solve LREs because of their number. Sometimes when learners were not able to solve a linguistic problem, a third or fourth member of the group was able to provide a correct solution. This supports the SCT perspective that if more learners are involved in an interaction and pool their knowledge, they have more possibilities to solve language-related problems. In fact, in a recent study with a focus group of 10 15-16 year old students of two proficiency levels carrying out a series of communicative group work activities in the Chilean EFL context, Sato and Viveros concluded that "[...] while proficiency does have an impact on learners' interactional behaviours, a collaborative mindset - a learner's psychological approach towards a partner or a task- may be a stronger mediating factor for L2 development" (2016: 91). In sum, our results seem to suggest a positive influence of the number of participants in a collaborative task on the occurrence and outcome of lexical LREs.

One issue worth mentioning in group work is the role of the observer, the learner that does not participate in an active way. Mackey (1999) had already claimed that this type of learner can still benefit from the task. A qualitative analysis of the data supports the idea that observers also benefit, which can be seen by looking at the posttests. In example 11, group 2 discusses the spelling of the word 'skiing'. The LRE is correctly solved by three members of the group; student G2S4 does not participate in the episode. However, he takes the role of an observer and benefits from the correctly resolved LRE; he changes his incorrect response in the pretest ('skiyng') to the correct response in the posttest ('skiing'). This example nicely demonstrates how the role of observer holds benefits and still offers opportunities for the learners to learn new knowledge:

Example 11

1 G2S2: Skiing

2G2S1: Skiing.

3 G2S2: With two I?

4G2S3: Yes with two I.

\begin{tabular}{|c|c|c|}
\hline LEARNER & PRETEST & POSTTEST \\
\hline G2S1 & skying (incorrect) & skiing \\
\hline G2S2 & skiing & go skiing \\
\hline G2S3 & --- & skiing \\
\hline G2S4 & skiyng (incorrect) & skiing \\
\hline
\end{tabular}

Fernández Dobao $(2014,2016)$ found that, although participants in small groups had fewer opportunities to contribute to the conversation actively, learners who participated as 
observers still benefited from the LREs. The present study supports this finding. While only in very few instances all four group members participated in an episode, they all showed instances of learning new knowledge and retention. In some episodes generated by groups it was found that the linguistic problem could not have been correctly resolved by only two learners, and a third one was needed. Qualitatively, this finding supports the SCT perspective that the more learners are involved, the more likely they are to solve language-related problems correctly, as their pool of knowledge is larger.

\section{CONCLUSION}

The present study investigated whether learner set up, pair vs. small group, influenced the frequency and outcome of LREs and whether it had an impact on L2 vocabulary learning. As seen above, the quantitative analysis of the data showed that no significant differences between the performance of pairs and groups could be reported, although the latter produced slightly more LREs than pairs and were able to solve more of those correctly. However, when the data were considered from a more qualitative perspective, groups could be seen to pool their resources and even benefit the member who did not actively participate in the discussion, the so-called silent observer. In any case, the findings from this study support the use of collaborative work, which leads learners to produce and correctly solve lexical LREs.

There are obvious shortcomings that should be acknowledged and that should lead to more research on this topic. The small sample $(n=30)$ has made it difficult to establish a clear difference between the production of pairs and groups. Future studies should, therefore, include a larger database. They should also consider whether pair vs. group interaction is affected by individual variables such as motivation (Al Khalil, 2016), proficiency (Sato \& Viveros, 2016) or learner engagement (García Mayo \& Azkarai, 2016; Philp \& Duchesne, 2016). Future studies should include more tasks to assess whether task type has an impact on interaction in pairs vs. small groups. In short, much more research on this topic should be carried out in order to create learning opportunities by means of learner collaboration in foreign language contexts.

\section{ACKNOWLEDGEMENTS}

The authors want to thank the students who took part in this study and the teacher who allowed the recording of the data. This work was supported by the Basque Government [grant number IT311-10] and Universidad del País Vasco (UPV/EHU) [grant number UFI11/06], which are hereby gratefully acknowledged. 


\section{REFERENCES}

Adams, R. \& Ross-Feldman, L. (2008). Does writing influence learner attention to form? In D. Belcher \& A. Hirvela (Eds.), The oral literate connection. Perspectives on L2 speaking, writing, and other media interactions (pp. 243-265). Ann Arbor, MI: The University of Michigan Press.

Al Khali, M. (2016). Insights from measurement of task-related motivation. In A. Mackey \& E. Marsden (Eds.), Advancing methodology and practice (pp. 244-262). New York, NY: Routledge.

Azkarai, A. (2013). Gender and task modality in EFL task-based interaction. Unpublished Doctoral Dissertation, University of the Basque Country, Spain.

Azkarai, A. \& García Mayo, M. P. (2012). Does gender influence task performance in EFL? Interactive tasks and language-related episodes. In E. Alcón Soler \& P. Safont-Jordá (Eds.), Discourse and language learning across L2 instructional settings (pp. 249-278). Amsterdam: Rodopi.

Basterrechea, M. \& García Mayo, M. P. (2013). Language-related episodes (LREs) during collaborative tasks: A comparison of CLIL and EFL learners. In K. McDonough \& A. Mackey (Eds.), Second language interaction in diverse educational contexts (pp. 24-43). Amsterdam: John Benjamins.

Crookes, G. \& Chaudron, C. (2001). Guidelines for language classroom instruction. In M. Celce Murcia (Ed.), Teaching English as a second or foreign language (pp. 29-42). Boston, MA: Heinle \& Heinle.

Fernández Dobao, A. (2012). Collaborative writing tasks in the L2 classroom: Comparing group, pair and individual work. Journal of Second Language Writing, 21, 40-58.

Fernández Dobao, A. (2014). Vocabulary learning in collaborative tasks: A comparison of pair and small group work. Language Teaching Research, 18, 497-520.

Fenández Dobao, A. (2016). Peer interaction and learning: A focus on the silent reader. In M. Sato \& S. Ballinger (Eds.), Peer interaction and second language learning: Pedagogical potential and research agenda (pp. 33-61). Amsterdam: John Benjamins.

Fernández Dobao, A. \& Blum, A. (2013). Collaborative writing in pairs and small groups: Learners' attitudes and perceptions. System, 41, 1-14.

Gánem-Gutiérrez, G. A. (2013). Sociocultural Theory and second language development: Theoretical foundations and insights from research. In M. P. García Mayo, J. Gutiérrez Mangado \& M. Martínez Adrián (Eds.), Contemporary approaches to second language acquisition (pp. 129152). Amsterdam: John Benjamins.

García Mayo, M. P. \& Alcón Soler, E. (2013). Negotiated input and output. Interaction. In J. Herschensohn \& M. Young-Scholten (Eds.), The handbook of second language acquisition (pp. 209-229). Cambridge: Cambridge University Press.

García Mayo, M. P. \& Azkarai, A. (2016). Does task modality impact on language-related episodes? In M. Sato \& S. Ballinger (Eds.), Peer interaction and second language learning: Pedagogical potential and research agenda (pp. 241-266). Amsterdam: John Benjamins.

(C) Servicio de Publicaciones. Universidad de Murcia. All rights reserved. IJES, vol. 17 (1), 2017, pp. 61-82 Print ISSN: 1578-7044; Online ISSN: 1989-6131 
Gass, S. \& Mackey, A. (2007). Input, interaction and output in second language acquisition. In B. Van Patten \& J. Williams (Eds.), Theories in second language acquisition. An introduction (pp. 175-199). Mahwah, NJ: Lawrence Erlbaum Associates.

González Sáinz, T. (1999). Juegos comunicativos. Español lengua extranjera. Madrid: SM.

Keck, C. M., Iberri-Shea, G., Tracy-Ventura, N. \& Wa-Mbaleka, S. (2006). Investigating the empirical link between task-based interaction and acquisition: A quantitative meta-analysis. In J. M. Norris \& L. Ortega (Eds.), Synthesizing research on language learning and teaching (pp. 91-131). Amsterdam: John Benjamins.

Kim, Y. (2008). The contribution of collaborative and individual tasks to the acquisition of L2 vocabulary. The Modern Language Journal, 92, 114-130.

Long, M. H. (1996). The role of the linguistic environment in second language acquisition. In W. C. Ritchie \& T. Bhatia (Eds.), Handbook of second language acquisition (pp. 413-468). New York, NY: Academic Press.

Long, M. \& Porter, P. (1985). Group work, interlanguage talk, and second language acquisition. TESOL Quarterly, 19, 207-227.

Mackey, A. (1999). Input, interaction and second language development: An empirical study of question formation in ESL. Studies in Second Language Acquisition, 21(4), 557-587.

Mackey, A. \& Goo, J. (2007). Interaction research in SLA: A meta-analysis and research synthesis. In A. Mackey (Ed.), Conversational interaction in second language acquisition (pp. 407-472). Oxford: Oxford University Press.

McDonough, K. (2004). Learner-learner interaction during pair and small group activities in a Thai EFL context. System, 32, 207-224.

Nassaji, H. \& Tian, J. (2010). Collaborative and individual output tasks and their effects on learning English phrasal verbs. Language Teaching Research, 14, 397-419.

Philp, J. \& Duchesne, S. (2016). Exploring engagement in tasks in the language classroom. Annual Review of Applied Linguistics, 36, 50-72.

Philp, J. \& Tognini, R. (2009). Language acquisition in foreign language contexts and the differential benefits of interaction. International Review of Applied Linguistics, 47, 245-266.

Pica, T. (1994). Research on negotiation: What does it reveal about second language learning conditions, processes and outcomes? Language Learning, 44, 493-527.

Richard, J. (2006). Communicative language teaching today. Cambridge: Cambridge University Press.

Sato, M. \& Viveros, P. (2016). Interaction or collaboration? Group dynamics in the foreign language clasroom. In M. Sato \& S. Ballinger (Eds.), Peer interaction and second language learning: Pedagogical potential and research agenda (pp. 91-112). Amsterdam: John Benjamins.

Storch, N. (1999). Are two heads better than one? Pair work and grammatical accuracy. System, 27, 363-374.

Storch, N. (2001). How collaborative is pair work? ESL tertiary students composing in pairs. Language Teaching Research, 5, 29-53.

Storch, N. (2005). Collaborative writing: Product, process and students' reflections. Journal of Second Language Writing, 14, 153-173.

(C) Servicio de Publicaciones. Universidad de Murcia. All rights reserved. IJES, vol. 17 (1), 2017, pp. 61-82 Print ISSN: 1578-7044; Online ISSN: 1989-6131 
Storch, N. \& Aldosari, A. (2013). Pairing learners in pair-work activity. Language Teaching Research, 17, 31-48.

Storch, N. \& Wigglesworth, G. (2007). Writing tasks: Comparing individual and collaborative writing. In M. P. García Mayo (Ed.), Investigating tasks in formal language learning (pp. 157177). London: Multilingual Matters.

Swain, M. (1985). Communicative competence: Some roles of comprehensible input and comprehensive output in its development. In S. Gass \& C. Madden (Eds.), Input in second language acquisition (pp. 235-253). Rowley, MA: Newbury House.

Swain, M. (2000). The output hypothesis and beyond. In J. Lantolf (Ed.), Sociocultural theory and second language learning (pp. 97-114). Oxford: Oxford University Press.

Swain, M. (2001). Integrating language and content teaching through collaborative tasks. The Canadian Modern Language Review, 58, 44-63.

Swain, M. (2006). Languaging, agency and collaboration in advanced language proficiency. In H. Byrnes (Ed.), Advanced language learning: The contribution of Halliday and Vygotsky (pp. 95108). New York, NY: Continuum.

Swain, M. \& Lapkin, S. (1998). Interaction and second language learning: Two adolescent French immersion students working together. The Modern Language Journal, 82, 320-337.

Swain, M. \& Lapkin, S. (2001). Focus on form through collaborative dialogue: Exploring task effects. In M. Bygate, P. Skehan \& M. Swain (Eds.), Researching pedagogic tasks: Second language learning, teaching and testing (pp. 99-118). London: Longman.

Swain, M. \& Lapkin, S. (2013). A Vygotskian sociocultural perspective on immersion education. The L1/L2 debate. Journal of Immersion and Content-Based Language Education, 1, 101-129.

Syndicate, U.C.L.E. (2001). Oxford Placement Test. Oxford: Oxford University Press.

Vygotsky, L. (1978). Mind in society: The development of higher psychological processes. Cambridge, MA: Harvard University Press.

Watanabe, Y. \& Swain, M. (2007). Effects of proficiency differences and patterns of pair interaction on second language learning: Collaborative dialogue between adult ESL learners. Language Teaching Research, 11, 121-142.

Wigglesworth, G. \& Storch, N. (2009). Pair versus individual writing: effects on fluency, complexity and accuracy. Language Testing, 26, 445-466.

Wood, D., Bruner, J. \& Ross, G. (1976). The role of tutoring in problem-solving. Journal of Child Psychology and Psychiatry and Allied Disciplines, 17, 89-100. 


\section{APPENDIX: VOCABULARY PRETEST}

Pre-activity

Name:

(To be cut by the researcher)

Code: (The researcher will fill this in)

Complete the following sentences. In order to do so, you will need to translate the word in parentheses. Try to find the best option and don't forget to use an article if necessary. In some cases the words might not be very common and perhaps there is no direct translation to English. In this case, try to find a synonym or alternative expression.

1. Two weeks ago I went to see (futuro). He (un adivino) to ask him about my (conocer) my boyfriend on a journey. Immediately I went to viajes) and bought (un billete) to Mexico. My flight (una agencia de in 10 minutes. I'm so excited! (salir)

2. I really like outdoor activities. I really like (ir en bicicleta). But there is more and more

(contaminación) and that worries me. If we don't do anything against it we will soon have to wear (máscaras antigás) when going outside.

3. My next trip will be (un crucero) to the Caribbean. I have it all planned out.

To save some money I will take a train to (coger) (un barco) to

(jefe) to give me advice on how to become rich. He told me as it

4. I asked my rains a lot in Seattle I should open una ferretería/jardinería) and sell (cortadoras de césped). I think that's a strange idea. What do you think? 